\title{
UN MARCO UNIVERSITARIO PARA LA EUROPA DEL SIGLO XXI
}

\author{
José T. Raga*
}




\section{RESUMEN}

Este artículo describe las condiciones en que sería posible una mejor interacción entre las universidades europeas. Tras un recorrido histórico por las diferentes etapas que ha vivido la institución universitaria en el viejo continente, se insiste en la vuelta a los propósitos originales de apertura y libertad que le dieron origen y se enumeran las características que constituyen el marco de interacción para la educación superior europea en el siglo XXI.

\section{ABSTRACT}

This paper describes the conditions that would help a better interaction among European universities. After an historic summary through the different stages that universities have undergone in the Old Continent, the author insists on going back to its original purposes of understanding and freedom, and he enumerates the characteristics of the interaction frame for the XXIst century's European higher education. 


\section{UN MARCO UNIVERSITARIO PARA LA EUROPA DEL SIGLO XXI}

Europa parece querer ser una sola comunidad también en educación. Al menos eso se deduciría de los pasos que vienen dándose en diferentes ámbitos educativos y del esfuerzo por la movilidad de estudiantes, profesores e investigadores, a través de los diferentes programas implantados al efecto, así como la proliferación fructífera de convenios de cooperación institucional entre universidades, que se incrementan de modo constante para, lo que muchos consideramos, el bien del sistema universitario europeo y el de cada país en concreto.

El objetivo se está imponiendo y calando tan hondo en la convicción de sus protagonistas que está consiguiendo orillar lo que han sido, desde hace ya algunos siglos, las barreras tradicionales de la vieja Europa. Países vecinos pero distanciados por una brecha fundada en la enemistad y las guerras; ignorados unos de otros por una Babel de lenguas diversas difíciles de conciliar; alejados por el intento decidido en la búsqueda de diferencias de carácter cultural, con olvido deliberado de la cultura común que, cuantitativa y cualitativamente, supera con creces los signos de diferenciación.

En ese escenario de diversidad, no ausente de conflictos, es la celebración del noveno centenario de la creación de la Universidad de Bolonia la ocasión propicia para que las universidades europeas dejen oír su voz manifestando su voluntad de servicio a un universo más coherente y más cooperativo.

Aquel 18 de septiembre de 1988 los rectores de la universidades europeas allí reunidos consideran que "el porvenir de la humanidad, en este fin de milenio, depende en gran medida del desarrollo cultural, científico y técnico que se forja en los centros de cultura, conocimiento e investigación en que se han transformado las auténticas 
Universidades". Desde esta consideración, afirmarán el principio fundamental de que: "Depositaria de la tradición del humanismo europeo, pero con la constante preocupación de atender al saber universal, la Universidad, para asumir su misión, ignora toda frontera geográfica o política y afirma la necesidad imperiosa del conocimiento recíproco y de la interacción de las culturas"”.

Se erige así la universidad como depositaria, por tradición, de la función social de la universalidad del saber, de la apertura al conocimiento, de la generosidad de difundirlo a todos los que estén dispuestos a aprenderlo, de compartirlo con el orbe universitario, sin mezquindad, en un intento de servir mejor a la humanidad en sus dimensiones materiales y espirituales, eliminando las carencias de uno y otro orden que esclavizan y sojuzgan a quien las padece.

A esa primera posición nítida y terminante, seguirá diez años después la Declaración de la Sorbona, suscrita entre los ministros representantes de Francia, Alemania, Italia y el Reino Unido, en la que los firmantes, recordando los momentos iniciales de la universidad europea, dejan patente que: "En aquellos tiempos los estudiantes y los académicos solían circular libremente y difundían con rapidez sus conocimientos por todo el continente. En la actualidad, gran número de nuestros estudiantes todavía se gradúa sin haber tenido la oportunidad de realizar un período de estudios al otro lado de las fronteras nacionales"

Un año después, se daría un paso más con la "Declaración de Bolonia", en la que los ministros de educación europeos afirmarán principios que no podemos silenciar. Entre ellos el de que: "La importancia de la educación y de la cooperación educativa en el desarrollo y fortalecimiento de sociedades estables, pacíficas y democráticas, se reconoce universalmente como prioritaria... " $\mathrm{O}$ bien, cuando afirma que: "La vitalidad y eficiencia de cualquier civilización

1 Magna Charta Universitatum, Bolonia, 18 de septiembre de 1988, Preámbulo, núm. $1^{\circ}$.

2 Magna Charta Universitatum, Bolonia, 18 de septiembre de 1988, Principios fundamentales, núm. 4.

3 Declaración conjunta para la armonización del diseño del Sistema de Educación Superior Europeo, La Sorbona, París, 25 de mayo de 1998, párrafo segundo.

4 The European Higher Education Area, Declaración conjunta de los ministros europeos de Educación reunidos en Bolonia el 19 de junio de 1999, párrafo tercero. 
puede medirse por la llamada que su cultura suponga para otros países. Necesitamos asegurar que el sistema de educación superior europeo adquiera un grado de atracción para el mundo entero equivalente a nuestras extraordinarias tradiciones culturales y científicas ${ }^{5}$ ".

La vuelta a los orígenes

Como bien puede desprenderse de lo dicho, una de las grandes preocupaciones instrumentales del nuevo Espacio Europeo de la Educación Superior es la de la movilidad de la comunidad universitaria, considerándose ésta un ingrediente sustantivo para el enriquecimiento intelectual y social.

Se trata, y así lo reconoce de modo expreso la Declaración de La Sorbona, de abrir de nuevo las puertas como fue el caso de la universidad en sus orígenes. El propio sentido de los studia, implicaba apertura a la vez que acción comunitaria. El mismo espaldarazo universitario de la Escolástica supone un gesto generoso de apertura del conocimiento, hasta ese momento enclaustrado en los ámbitos monacales, para ponerlo al servicio y disposición de la sociedad. Una apertura del saber que se corresponde con una mayor y más abierta comunicación de sus protagonistas y cultivadores.

La movilidad es un hecho histórico en los comienzos de la universidad y en los primeros siglos de su andadura. Recuérdese, a título de simple referencia, la movilidad inherente a un Santo Tomás de Aquino, a un San Alberto Magno o a un Abelardo, como enseñantes, como disertantes o como responsables de lo que hoy, sin duda, calificaríamos como grandes proyectos de investigación científica de carácter transnacional.

Movilidad evidente en los alumnos cuando contemplamos la flexibilidad para trasladarse a la Universidad de Oxford desde la colina de Santa Genoveva en los aledaños de París, tras los problemas de convivencia surgidos en aquel lugar. O como lo hicieran los estudiantes de la primera, aunque fugaz, universidad española en Palencia a la Universidad de Salamanca, al producirse el cierre de la primera de ellas.

5 The European Higher Education Area, Declaración conjunta de los ministros europeos de Educación reunidos en Bolonia el 19 de junio de 1999, párrafo octavo. 
La apertura es una nota esencial de la universidad. En ella el saber no se atesora sino que se difunde. La codicia, propia de la concurrencia conflictiva de intereses, no tiene espacio en la universidad; ésta, está llamada a compartir. Es el gran activo con el que se encuentra la comunidad universitaria. Compartir y participar, en un clima de libertad sin el que no cabe esta institución. Así se deduce de no pocos pasajes que contemplan aquella universidad del siglo XIII. "El Estudio es el ayuntamiento, la unión de maestros y escolares que es hecho en algún lugar con voluntad y entendimiento de aprender los saberes" ${ }^{\prime \prime}$, dirá Alfonso X El Sabio. O, apenas unos cinco años antes, se nos habría dicho que la vocación universitaria, para el bien de la sociedad, es la que hace que se consagre "a la investigación, a la enseñanza y a la formación de los estudiantes, libremente reunidos con sus maestros animados todos por el mismo amor al saber ${ }^{7 "}$. Sentidos de comunidad y de libertad, sin los que la tarea universitaria se hace imposible.

Será la aparición del Estado Nación la que acabará con la apertura de la universidad, no para enclaustrarla de nuevo en los monasterios del saber, sino para atenazarla al servicio del poder político y de sus intereses privativos. La universidad, centro de creación del saber, se convierte así en objeto de control y atesoramiento por parte del Estado pues, donde hay libertad y capacidad de creación, existe el riesgo de la crítica y de la rebelión.

El control de la universidad se convierte, de este modo, en la exigencia para el pacífico desarrollo de la actividad pública, y si se nos apura, en requisito para la propia seguridad del Estado. Configurada desde esta estrategia, pierde una de sus notas de grandeza: la generosidad, la entrega desinteresada. Así, el saber ya no es el patrimonio que corresponde a toda la humanidad, a quien también se debe el que tiene el privilegio de descubrirlo, sino que pasa a ser riqueza de un Estado o de una comunidad determinada, quienes están legitimados a su atesoramiento y a usarlo como arma de competitividad.

6 Alfonso X El Sabio, Libro de las Leyes o Partidas (1256-1263), Segunda Partida, Título XXXI, 'De los Estudios en que se aprenden los saberes, e de los maestros e de los escolares'.

7 Alejandro IV, Carta a la Universidad de Paris el 14 de abril de 1255, Introducción, 'Bullarium Diplomatum...' Tomo III, Turín, 1958, p. 602. 
Lo propio, en cuanto perteneciente al haber singular, se sitúa, a partir de estas premisas, en un orden valorativo superior: es anterior y superior a cualquier otra capacidad, descubrimiento o aportación. Los sistemas universitarios se diversifican según las preferencias públicas o del sector público, no necesariamente coincidentes con los objetivos sociales.

La cotización de lo propio y el desconocimiento de lo ajeno conducen al no reconocimiento de lo acreditado fuera de las fronteras de una determinada nación. Lo que fuera en sus inicios un campo llano y fértil de convivencia y de intercambio se convierte en fortalezas que apenas disponen de estrechos tragaluces para disponer de una tenue iluminación. La escala del saber se reduce, de forma sensible, al espacio de la jurisdicción en la que se ejerce la actividad. Siendo la apertura un privilegio.

Nada de extraño tiene pues que la universidad, terminando el siglo XX y en los comienzos del XXI, añore los momentos de su grandeza y quiera retomar, de forma generalizada, aquella universalidad del saber que caracterizaron sus períodos de mayor gloria. Por ello, aunque resulte escandaloso, podría afirmarse, con pocas probabilidades de error, que la universidad europea del siglo XXI reclama volver a sus fuentes, naturalmente que con las diferencias lógicas de tiempo y de escenario.

La pretendida apertura de la Unión Europea y no sólo de ella

El siglo XX que, en su primera mitad constituye motivo de vergüenza para la vieja Europa, ofrece a ésta la oportunidad para reencontrarse y enmendar su comportamiento. Cuarenta años de guerras, de enfrentamientos, de divisiones de lo que era común y que, quizá, sólo como común tenía sentido, arrojan un único signo positivo: el ferviente deseo de que las experiencias de este tenor no volvieran a producirse en una Europa que deseaba vivir en paz y en prosperidad.

El proceso de integración económica de Europa de la mano de sus artífices, todos ellos grandes humanistas, pretendía, sin duda, ofrecer un proyecto de vida a los ciudadanos europeos en el que fuera relevante la convivencia pacífica entre pueblos y naciones. 
No es este el lugar ni el momento para valorar los éxitos obtenidos, y que se muestran de manera muy especial en la apertura de fronteras y en el compromiso solidario con aquellas regiones con escasez de medios para fomentar su propio desarrollo.

Pero, digámoslo nosotros, Europa no puede ser simplemente la consecución de la libre circulación de mercancías y de flujos financieros; triste fin para un viejo continente. El verdadero reto europeo está en la circulación libre de personas, sin discriminación posible por origen o cualquier otra causa. Y cuando hablamos de personas no nos referimos exclusivamente a la dimensión corpórea de éstas, sino que pensamos también en su dimensión intelectual, en su capacidad y habilidad, en su potencialidad y competencia. Y ello, además, tanto para obtener aquellas capacidades como para entregarlas al servicio de la sociedad europea.

Estamos hablando, en definitiva, de la libertad operativa del mundo del conocimiento: de su creación y de su difusión, de su adquisición y de su reconocimiento. Europa necesita avanzar para eliminar trabas a esta libertad, sin la cual no cabe la libertad del espacio geográfico europeo. El no reconocimiento de competencias y de habilidades y de sus certificaciones (titulaciones de grado, pregrado y posgrado) es, quizás, el proteccionismo más severo y humillante de cuantos se pueden practicar.

En este aspecto, cabría distinguir actitudes bien diferenciadas: las que practican las personas, las de las instituciones universitarias y las de los Estados y colegios profesionales. Sin temor a errar, y para honor de la persona humana, ésta considera, generalmente, en plano de igualdad o de equivalencia el nivel del conocimiento, cualquiera que sea el lugar en el que se haya adquirido y cualquiera que sea la nacionalidad de quien lo adquirió. Diríamos, en este sentido, que la permeabilidad horizontal es prácticamente plena.

Algo semejante, aunque en menor grado, ocurre cuando se trata de las universidades o centros de educación superior. Buena muestra de ello es la actitud de las primeras cuando se trata de convalidar parcialmente estudios realizados en el extranjero, para su continuación en el sistema nacional. 
Sin embargo, la actitud de los Estados y, más aún, la de los colegios profesionales, en una pretendida tutela y garantía del ejercicio de la profesión en su ámbito jurisdiccional, es restrictiva y claramente discriminatoria, otorgando, al menos en el corto plazo, una ventaja comparativa a los titulados de la propia nacionalidad. Y decimos a corto plazo, porque a plazo largo empobrece el conocimiento y a aquellos que lo adquieren.

El espacio europeo de educación superior, un paso esperanzador

Lo que en el argot al uso denominamos el proceso Bolonia es la oportunidad para recobrar aquel carácter del que se vio privada la universidad europea: apertura, libertad y universalidad.

La tarea no está ausente de dificultades. Entre ellas, por ejemplo, no es menor el conjunto de estructuras e intereses que los sistemas han venido creando en torno a la educación superior. Estructuras que exigen hoy la generosidad que discutieron en un período lejanamente anterior.

El proceso de acercamiento, que no de coincidencia, se inicia desde la diversidad, por lo que sólo podrá tener éxito, al menos en esta etapa de construcción, si reconoce las particularidades impuestas por una tradición ya secular y, consecuentemente, renuncia ab initio a una vana pretensión como sería la homogeneidad.

El proyecto de Bolonia aspira, con modestia, a que los distintos países integrados en el sistema sean menos diferentes de lo que son en la actualidad. Es más, ya sería un activo importante que, en el espacio europeo, existiera transparencia para la movilidad. Transparencia, cuando estamos hablando de títulos y grados, significa la comprensión plena del alcance de las competencias de unos y otros y de sus equivalencias leales con los que operan en el sistema.

Esta es una de las funciones, nada vanas, que se le otorga a un documento, imprescindible en un espacio amplio y sistemas diversos, como es el suplemento europeo al título. A través de él, tanto las universidades para continuar estudios como las administraciones públicas y los empleadores privados tendrán una información plena 
del nivel de conocimientos y de capacitación profesional de aquel titulado a quien corresponda el documento.

Elementos formales y elementos sustantivos deberán estar presentes en los esfuerzos que los sistemas educativos tendrán que realizar para el buen fin del proceso en el que hemos cifrado buena parte de nuestras esperanzas. Conviene decir, por ser de justicia, que buena parte de los gobiernos del espacio europeo, remisos en otras materias a limitar su voluntad política, han asumido esto como un reto de Estado al que hay que dar fiel cumplimiento.

En el caso español es bien notorio lo que acabamos de decir. En la vigente Ley Orgánica de Universidades, puede leerse: "En el ámbito de sus respectivas competencias, el Gobierno, las Comunidades Autónomas y las Universidades adoptarán las medidas necesarias para la plena integración del sistema español en el espacio europeo de enseñanza superior ${ }^{8}$. No se trata de una simple declaración voluntarista de principios, sino del empeño de una tarea: la plena integración del sistema español en el espacio europeo de enseñanza superior, para la que se adoptarán las medidas necesarias que la garanticen.

Igual de concluyente es la ley en aspectos relevantes del proceso de Bolonia. Así, en cuanto a la movilidad, encontramos: "El Estado, las Comunidades Autónomas y las Universidades fomentarán la movilidad de los estudiantes en el espacio europeo de enseñanza superior a través de programas de becas y ayudas y créditos al estudio o, en su caso, complementando los programas de becas y ayudas de la Unión Europea". Y también: "El Estado, las Comunidades Autónomas y las Universidades fomentarán la movilidad de los profesores en el espacio europeo de enseñanza superior a través de programas y convenios específicos y de los programas de la Unión Europea ${ }^{10}$ ".

8 Ley Orgánica 6/2001, de 21 de diciembre, de Universidades (B.O.E. núm 307, de 24 de diciembre de 2001), art. 87.

9 Ley Orgánica 6/2001, de 21 de diciembre, de Universidades (B.O.E. núm 307, de 24 de diciembre de 2001), art. 88-4.

10 Ley Orgánica 6/2001, de 21 de diciembre, de Universidades (B.O.E. núm 307, de 24 de diciembre de 2001), art. 89-4. 
Ese carácter imperativo de la norma está presente en todo lo que hace referencia al espacio europeo: títulos y planes de estudio, medida del haber académico basada en el crédito europeo, entre otros aspectos.

\section{Conclusión}

El momento que vive la universidad europea no puede ser más fascinante. Se trata de una oportunidad para hacer bien lo que en otras épocas, y debido a intereses extrauniversitarios, perturbó la imagen y la propia función de la universidad.

El empeño de los gobiernos y, más aun, el entusiasmo que se detecta en la propia institución universitaria, hace de esta oportunidad algo más que una ocasión para el cambio: se trata, en realidad, de un verdadero proyecto universitario para el siglo veintiuno. 


\section{REFERENCIAS BiBLIOGRÁFICAS}

ACADEMIC COOPERATION ASSOCIATION, Internationalisation in the Sector of New Higher Education in Europe (17 country essays on the nonuniversity sector). Academic Cooperation Association (ACA). May 1999.

Alcantud Marín, FRAncisco (Edit.), Universidad y diversidad, Valencia, 1997.

Alejandro IV, Carta a la Universidad de París el 14 de abril de 1255, Bullarium Diplomatum..., Turín, 1958.

Alfonso X El Sabio, Libro de las Leyes o Partidas (1256-1263).

BRicall, Josep M, Universidad 2 mil, Conferencia de Rectores de las Universidades Españolas (CRUE), Madrid, 2000.

Burgen, Arnold, Metas y proyectos de la Educación Superior. Una perspectiva internacional, Fundación Universidad-Empresa, Madrid, 1999.

Declaración Conjunta para la armonización del diseño del Sistema de Educación Superior Europeo, La Sorbona, París, 25 de mayo de 1998.

Green, A, Wolf, A, Leney, T, Convergence and Divergence in European Education and Training Systems, Institute of Education, University of London, Bedford Way Papers, 1999.

Grimm, D, Internationalization of Engineering Education in Europe, Ecole Centrale Paris, 1999.

KIRSTEIN, J, Information on Learning Structures in Higher Education in the EU/EEA Countries. Survey for the project 'Trends in lerning structures of higher education in the EU/EEA' based on the contributions for the national rectors', conferences and NARICs, May 1999. 
Landfried, K, Lange, J, Perspectives of Universities in Germany. Presentation at the Meeting of Directors General of Higher Education and Chairpersons of Rectors, Conferences, Weimar, 1-2 March 1999.

Ley Orgánica 11/1983, de 25 de agosto, de Reforma Universitaria (B.O.E. $n^{\circ} 209$, de 1 de septiembre).

Magna Charta Universitatum, Bolonia, 18 de septiembre de 1988.

Michavila, Francisco, Los límites de la educación, Casa de América, Madrid, 2000.

Michavila, Francisco, La salida del laberinto. Crítica urgente de la Universidad, Editorial Complutense, Madrid, 2001.

Pedrosa, J, Notes concerning the preparation of the Bologna meeting (Sorbone Declaration), Aveiro, March, 1999.

Porta, Jaume, Lladonosa, Manuel, (Coords.), La Universidad en el cambio de siglo, Alianza Editorial, Madrid, 1998.

RAGA, JosÉ T, "La universidad como centro de estudio, convivencia y participación", en Cuadernos de Sociedad, núm. 14, Número Extraordinario, Editorial Fundación Independiente, Madrid, 1997.

RAgA, José T, "L’università in Spagna", en Il Nuovo Areopago -Rivista trimestrale di cultura-. Anno 16, numero 4, Ed. Nuova Compagnia Editrice, Ottobre-Dicembre 1997.

The European Higher Education Area. Joint Declaration of the European Ministers of Education, Covened in Bologna on the 19th of June 1999.

Tugores Ques, JuAn, "La universidad pública del S. XXI: Un compromiso con la sociedad", en Quaderns Institucionals, Escola d'Empresarials, Universitat de Barcelona. Núm. 1, juny 1999. 
